\title{
ESSE ESPAÇO NÃO EXISTE! A UFG, SEUS ESPAÇOS E SEUS DISCURSOS
}

Ana de Pellegrin ${ }^{1}$, Claudio luiz Abreu Fonseca², Rusvênia luiza B. R. DA SILVA ${ }^{3}$

\begin{abstract}
Resumo: Este artigo tem como objetivo analisar o espaço universitário na perspectiva da ambiência e dos seus discursos. Empreende-se uma tarefa complexa, pois a universidade, ao mesmo tempo em que é lugar de produção de conhecimento, não tem sido investigada da perspectiva dos grupos sociais que nela circulam. Os diversos grupos que a frequentam, a vivenciam e constituem sua cotidianidade no espaço universitário podem imaginar ser esse espaço um ambiente plural, ao mesmo tempo em que podem crer que os discursos ali produzidos pertencem a esse lugar. Procuramos perceber de que maneira as vivências, os circuitos espaciais e as narrativas constituem discursos, bem como o contexto sócio histórico e cultural a que estão articulados.
\end{abstract}

Palavras-chave: UFG, pátio humanidades, espaço, lugar, discurso, produção de sentidos.

\section{ESSE ESPAÇO NÃO EXISTE! THE UFG, ITS SPACES AND ITS SPEECHES}

Abstract: This article aims to analyze the university space from the perspective of the environment and its speeches. A complex task is undertaken, since the university, at the same time as the place of knowledge production, has not been investigated from the perspective of the social groups that circulate in it. The various social groups that attend, experience and constitute their daily life in the university space can imagine that this space is a plural environment, while at the same time they can believe that the discourses produced there belong to this place. We try to understand how the

\footnotetext{
$1 \quad$ FEFD /UFG - adpellegrin@uol.com.br

2 FL/UFMT - clafonseca@hotmail.com

3 IESA /UFG - rusvenia@gmail.com
} 
experiences, the spatial circuits and the narratives constitute speeches, as well as the socio-historical and cultural context to which they are articulated.

Keywords: UFG, patio humanidades, space, place, speech, meanings production.

¡ESTE ESPACIO NO EXISTE! LA UFG, SUS ESPACIOS Y SUS DISCURSOS

Resumen: Este artículo está destinado a analizar el espacio universitario desde la perspectiva del entorno y sus conversaciones. Se ha investigado desde la perspectiva de los grupos sociales que circulan en él. Los distintos grupos sociales que asisten, experimentan y calculan su vida diaria en el espacio universitario, pueden imaginar que este espacio es un entorno plural, mientras que en el mismo tiempo pueden creer que los discursos producidos en ese momento. Estamos tratando de entender las experiencias, los circuitos espaciales y las narrativas de habla, así como el contexto socio-histórico y cultural a lo que se articulan.

Palabras clave: UFG, patio humanidades, espacio, sitio, discurso, producción de sentidos.

A universidade tal como conhecemos tem suas finalidades próprias ligadas à formação superior nas mais diversas áreas do conhecimento e pautadas pela pluralidade de saberes e de ideias. Configura-se também como lugar de investigação, de produção de novos conhecimentos e de aprimoramento de técnicas e saberes já conhecidos. A universidade é um espaço pensado por diferentes perspectivas. As mais frequentes associam-na diretamente com a sua dimensão primordial: lugar de produção de conhecimento; campo de disseminação de ideias; lócus de criação e formação de pesquisadores e profissionais. Desejamos neste texto perceber a universidade pelo seu espaço: pensá-la na perspectiva de sua ambiência. Notamos que não há um conjunto volumoso de estudos que se colocam esse desafio. Sendo assim, não descartamos modelos explicativos de reflexões pretéritas que se puseram a pensar a universidade a partir da relação sujeito - conhecimento.

No ambiente universitário convivem necessariamente distintos e diversos grupos humanos; estudantes, docentes, trabalhadores dedicados às tarefas técnico-administrativas, à vigilância patrimonial, à limpeza, à alimentação, entre outros. Todas essas pessoas possuem, por assim dizer, um vínculo formal com a instituição, ligado as suas atividades laborais e/ou acadêmicas. 
Ocorre que há também um contingente de pessoas que frequenta o ambiente universitário por motivações diversas. Além do ensino e da pesquisa, as universidades brasileiras, sobretudo as públicas, desenvolvem um corpo de ações no campo da extensão universitária.

Magalhães (2014) realizou uma pesquisa no campo da Arquitetura e Urbanismo procurando pensar a relação entre o câmpus universitário e o espaço urbano. Segundo suas análises os câmpus têm uma importante influência, em geral, em relação aos seus espaços de entorno, pois como são equipamentos associados a outros espaços podem constituir forças capazes de configurar o meio envolvente e de influenciar a qualidade de vida dos que os habitam. No desenvolvimento de sua análise esse autor defende ser o câmpus um equipamento urbano singular do espaço público da cidade, resultado de um longo processo de transformação pelo qual passaram a universidade e a sociedade. No entanto, uma analogia entre a realidade universitária brasileira e outras leva o autor a afirmar que

Os serviços que os câmpus brasileiros oferecem - mesmo nos maiores, são restritos e deficientes. Os alojamentos para estudantes oferecem poucas vagas e não há moradia para os professores. Serviços, como transportes, só funcionam com regularidade nos dias úteis e supermercados e outros comércios necessários à subsistência são raros e, na maioria dos casos, inexistentes. Os câmpus brasileiros não são autossuficientes; dependem ainda e muito das cidades em que estão localizados e o termo cidade universitária não passa de uma aspiração que nunca se realizou. (2014, p.21).

Veja-se o caso da UFG. Há um grande número de pessoas que circula no câmpus, frequentando as unidades acadêmicas de forma regular, sistemática ou mesmo eventual, por conta dos projetos de extensão (atividades artísticas, atividades físico-esportivas, ações específicas no campo da saúde de um modo geral, eventos musicais, debates, rodas de conversa, projeção de filmes etc.). Algo interessante acontece aí, a partir do entendimento da universidade como lugar de vivência da cultura, especialmente de vivências lúdicas. Há um conjunto de atividades que acontecem em determinados espaços e que são parte do trabalho de alguns sendo, ao mesmo tempo, vivenciadas como lazer por outros grupos. No entanto ainda é preciso perceber que esse espaço não abrange todas as necessidades para maior permanência da comunidade no câmpus. Esse desafio é uma marca específica da UFG, bem como das diversas universidades no Brasil. 
Ao longo desse texto iremos desenvolver uma reflexão que se inicia pensando o espaço universitário como um todo, por meio do conceito de circuitos espaciais e em seguida analisaremos o pátio humanidades, mais especificamente, os discursos ali produzidos.

\section{REFLEXÕES GERAIS SOBRE O ESPAÇO UNIVERSITÁRIO}

Observando o ambiente da UFG é possível identificar muitos lugares que atraem determinados grupos de pessoas ou que atendem a determinados interesses. Considerando os grupos sociais - e tendo como referência as pesquisas desenvolvidas pelo antropólogo José Guilherme Cantor Magnani na periferia e na região central da cidade de São Paulo nas décadas de 1970 e 1980 -, é possível identificar, por exemplo, um circuito marcadamente estudantil, formado pelo DCE, Centros Acadêmicos diversos, cantinas, pátios cobertos (Humanidades, Física, Química/ICB), Casa do Estudante, Hall da Faculdade de Letras, Gramado do DCE/RU, Gramado da EMAC/Centro de Convivência, Gramado da FAV/Biblioteca, Estacionamento da Reitoria, dentre outros espaços.

Neste circuito estudantil, vemos que alguns grupos tendem a ocupar mais expressivamente alguns espaços, como por exemplo, os estudantes do curso de Letras - Libras que convivem com frequência no vão da Faculdade de Letras. Ou os estudantes de História e dos cursos de comunicação que convivem no Pátio Humanidades. Ou mesmo estudantes de vários cursos que se encontram na fila do Restaurante Universitário, nos horários de almoço e jantar.

É possível identificar grupos sociais não apenas por sua atividade principal dentro do câmpus, mas também pela etnia; teríamos aí um grupo expressivo de pessoas indígenas, vários estudantes que circulam pelo câmpus em um calendário específico de atividades, tanto nos cursos formais quanto na Licenciatura Intercultural de povos indígenas situados na região Araguaia-Tocantins.

Pensando nos distintos interesses, podemos imaginar outro circuito, aqui identificado como físico-esportivo, formado pelas instalações e equipamentos da Faculdade de Educação Física e Dança (piscina, quadras, campo de futebol, pista de atletismo, laboratório de treinamento resistido), instalações e equipamentos do CECAS (Centro de Esportes Câmpus Samambaia). Da mesma forma, seria possível pensar em um circuito artístico, constituído pela Galeria de Artes da FAV, Teatro da EMAC, Cine UFG, Café das Letras, Centro de Cultura e Eventos. Para além do ambiente do câmpus, teríamos o Centro Cultural da 
UFG, o Planetário e o Museu Antropológico configurando-se como equipamentos de cultura e lazer também ligados a esta rede da Universidade.

A apropriação do espaço pelos grupos humanos que circulam pelo câmpus é bastante diversa durante a semana, quando todas as atividades tendem a funcionar plenamente. Nos fins de semana e feriados a Universidade é fechada, e os equipamentos só são utilizados por ocasião de algum evento específico. Vale ressaltar que no segundo semestre de 2018, com vistas a estimular as atividades de extensão e a vivência no câmpus, surgiu um projeto chamado Curta o Campus, organizado por uma equipe de professores de diversas unidades e coordenado pela professora Lucilene da PROEC, que teve boa adesão da comunidade local nas suas duas edições (setembro e novembro de 2018).

No final da década de 1990, em pesquisa realizada na cidade de Campinas-SP, que versava sobre as relações entre espaço vazio e espaço de lazer, em especial sobre como se dava a apropriação desses vazios urbanos pela população, foram encontrados alguns achados interessantes na observação da área da Universidade Estadual de Campinas (Unicamp) ${ }^{4}$.Os chamados vazios circunstanciais da Unicamp - ruas, estacionamentos, gramados de rotatórias - chamavam a atenção pelo uso como equipamento de lazer, sobretudo aos finais de semana, por grupos sociais diversos com interesses distintos: ciclistas, skatistas, patinadores, jogadores de bets (taco), futebol, beisebol, peteca, praticantes de caminhada e corrida. Registre-se que o câmpus da Unicamp permanece aberto irrestritamente aos pedestres nos finais de semana, havendo controle mais rígido na entrada e saída de veículos.

Considerando que as atividades de lazer encontradas na Unicamp eram muito diversas e os vazios do câmpus não foram planejados para esta finalidade, com frequência se observava uma intervenção dos próprios grupos no espaço, de modo a adaptá-lo para suas atividades. Skatistas e patinadores construíam obstáculos para realizar manobras. Jogadores de peteca e futebol levavam e instalavam rede e traves.

Se essas pessoas transportavam seus próprios materiais para brincar e jogar no câmpus, intervindo no ambiente durante o tempo de duração de suas atividades, verificou-se também uma intervenção permanente realizada por

4 Conforme De Pellegrin (1999), entre as áreas selecionadas para a pesquisa estava o Distrito de Barão Geraldo, onde se localiza a Unicamp. Em função disso, o uso dos equipamentos da Universidade foi observado sistematicamente, bem como os espaços vazios e suas diversas apropriações. 
outro grupo de interesse. Uma parede de escalada foi montada por um grupo de alpinistas em um dos prédios da Faculdade de Educação Física. Este achado é interessante porque nos repõe a questão da espacialidade, do cheio e do vazio, acostumados que estamos a pensar no espaço livre apenas no sentido da horizontalidade e nas áreas construídas como ambientes não passíveis de serem objeto de intervenção.

A UFG, por sua vez, tem muitas áreas verdes e restos de mata. Estes ambientes tendem a ser esquecidos de certa maneira, mas é possível observar que há uma ocupação das áreas verdes e gramados, tanto para descanso como para convivência. Já foram observados inclusive praticantes de slack line aproveitando árvores no gramado vizinho ao Instituto de Ciências Biológicas, por exemplo. Trata-se de uma atividade que também requer um equipamento próprio que o praticante carrega consigo e instala em árvores de sua preferência.

Ao analisar o ambiente urbano, a partir das categorias "cheio" e "vazio", o argentino Santiago Barbuy (1980) identifica uma tendência para o cheio, isto é, para o construído, lotado e saturado. A edificação lucrativa tende a qualificar o espaço vazio apenas como valor comercial. A importância dos vazios urbanos é que eles são frequentemente referências culturais, ambientais, espaços onde as finalidades principais poderiam ser o encontro e o convívio humanos, tornando-se essencialmente lugares de fruição.

Em que pese o fato de a universidade ser um órgão estatal, ela não é uma ilha apartada do ambiente urbano. Se há planejamento, se há política de manejo do espaço do câmpus, há que se pensar na espacialidade de um modo mais amplo e nas tendências que outros pesquisadores já apontaram e sobre as quais nos deixaram pistas.

Quando se planeja uma intervenção como a construção de um prédio, por exemplo, seria igualmente necessário planejar o espaço vazio que acompanharia este preenchimento do ambiente. Mais que isso, para criar identidade cultural da comunidade com este lugar e com as modificações no espaço, seria importante que este vazio representasse um convite, e não uma proibição, à intervenção desses grupos humanos. A identidade cultural de um grupo com um lugar somente pode concretizar-se por meio da intervenção ativa sobre ele. Pensando no planejamento dos espaços de lazer para crianças, a arquiteta Mayumi Souza Lima afirmava que 
É preciso, pois, deixar o espaço suficientemente pensado para estimular a curiosidade e a imaginação da criança, mas incompleto o bastante para que ela se aproprie e transforme esse espaço através de sua própria ação (LIMA, 1989, p.72).

Recuperando a hipótese de que o espaço vazio seja valorizado como lugar de fruição, consideramos que este aspecto inclui a possibilidade de uma experiência estética, que é uma particularidade do ser humano. Como nos lembra Sánchez Vázquez (1999), as chamadas pinturas rupestres, registradas nas paredes das cavernas, e que hoje se transformam em objetos estéticos aos nossos olhos modernos, respondiam a outras necessidades específicas dos grupos humanos daquela época. As diversas formas de pintura que hoje contemplamos são formas de respostas às questões do nosso tempo.

Estejamos atentos para o fato de que a educação dos sentidos não é fenômeno que se observa restritamente no interior de instituições de ensino. A formação dos cinco sentidos é um trabalho de toda a história do mundo até aqui (MARX, 2004, p. 110). Sob essa perspectiva nos ateremos a pensar o espaço do Pátio Humanidades, considerando que esse dossiê fora estimulado tendo esse espaço como ponto de partida para que, a partir do que ele revela, seja possível traçar uma reflexão fecunda sobre a universidade como um todo. Isso posto, nos propomos a apurar o nosso olhar e voltá-lo para a realidade instalada ali nos últimos anos, em especial, as tensões e os discursos.

\section{Perspectivas Espaciais do Pátio Humanidades}

\footnotetext{
"Independe de tamanho e de características físicas a atribuição da alcunha "lugar" às diversas percepções do homem sobre os espaços vividos. Da lareira à nação, é vasta a gama de fenômenos que podem ser tidos como lugares”. Yi-Fu Tuan (1975)
}

Movimentamos nos lugares numa perspectiva do eu cinestésico, porém nossa experiência corporal nos ajuda a enxergar as coisas e construir de duas maneiras: tanto de modo intencional quanto, também, como parte do mundo e da natureza. Tudo se faz a partir da maneira como nos dispomos espacialmente. Nossos juízos se ligam ao mundo que nos é dado sob diferentes aspectos: por meio de uma experiência direta engendramos relações lógicas, nos relacionamos com os objetos que estão numa certa disposição e modificamos a nossa relação em função do movimento. 
O Pátio Humanidades é um espaço demarcado por uma organização dada: um vão - quatro portas entradas/saídas de um lado, duas da Faculdade de Informação e Comunicação - FIC e duas da Faculdade de História - FH; e duas portas de entrada/saída do outro, do Instituto de Física. Na FIC e na FH as portas estão sempre abertas e por elas circulam pessoas que se direcionam de um prédio a outro, trabalhadores e estudantes que cotidianamente vivenciam esse espaço. Do lado oposto, as portas fechadas são lugares de ficar, de sentar, de fumar, de namorar, de encostar (Croqui 1). Lugares estáticos que constituem outro tipo de comunicação e outro movimento no campo da existência.

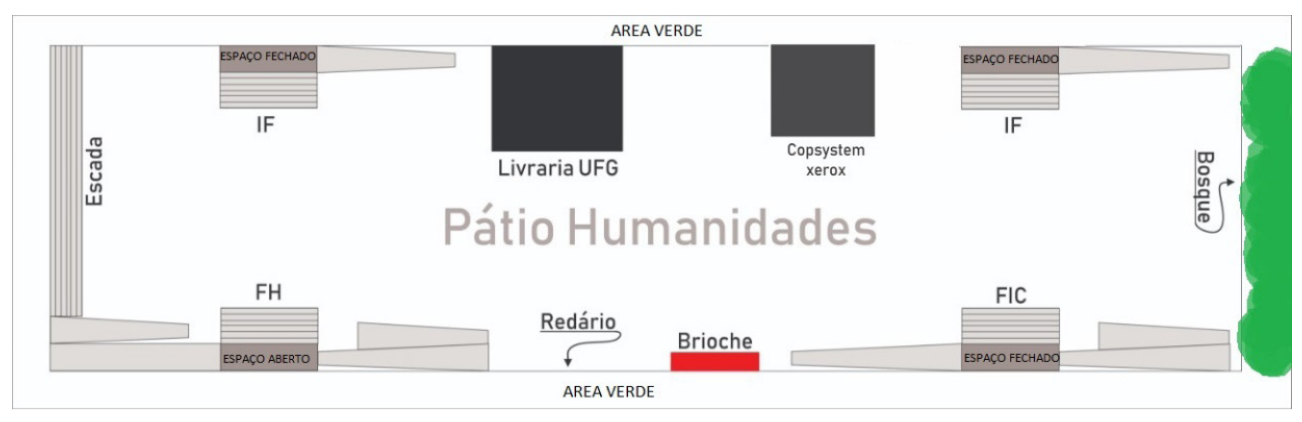

AdAPTADO DE KARINA ANDRÉ - FAV, 2018.

Apesar de opostas ambas as experiências são conectadas. Defronte à FIC a visão da porta fechada do Instituto de Física apresenta um corredor que se opõe à imagem do pátio. $\mathrm{O}$ pátio parece não ser absorvido pelo Instituto de Física como lugar: a porta fechada impede o estreitamento das relações entre os lugares. O IF, diferente dos prédios da FIC e da FH, se conecta a dois pátios, mas se relaciona apenas com um deles.

Importa ressaltar que o fechamento das portas do IF é parte de um conjunto de medidas tomadas como forma de proteção do patrimônio da UFG, uma vez que a segurança do patrimônio é uma preocupação constante da gestão da universidade em todos os seus níveis. Outras medidas tomadas no segundo semestre do ano passado foram o fechamento do redário (área aberta e arborizada, com instalação de mourões para redes) que fica entre a FIC e a FH e também a retirada das mesas e cadeiras do pátio.

As medidas de fechamento dos espaços não foram inauguradas com as ações que, no âmbito institucional, ocorreram no pátio. Antes dessas ações e da retirada das mesas, a tela de acesso ao bosque que faz fronteira com os pátios das Humanidades, da Física/Química, foi fechada há mais de uma década. Isso indica que um tipo de política espacial tem sido adotada para lidar com 
os problemas advindos do tráfico de drogas que se instalou nesse ambiente nos últimos anos. O fechamento dos espaços de circulação.

Acreditamos que seja possível traçar possibilidades de leitura da universidade, em específico, a partir dos seus lugares/circuitos espaciais de convivência, por meio dos discursos que emanam deles. Dentro do campo de conhecimentos da Geografia, dos estudos do Lazer e também das Letras nosso olhar se voltou a analisar os discursos presentes e ausentes que emanam dos espaços, primeiramente de modo mais geral, mas também com foco nesse pátio, outrora também conhecido como "Pátio do ICHL".

O título desse artigo, na primeira parte dele, a frase "Esse espaço não existe!" é um exemplo de um discurso no/do pátio. O texto está registrado no chão, no alpendre de uma das portas que dá acesso ao Instituto de Física (IF). Ao fazer um trabalho de observação no pátio, coletamos alguns desses discursos e esse é um dos que para nós indica muitas possibilidades de leitura.

A frase "Esse espaço não existe!" começa com a indicação do pronome demonstrativo esse, que designa indivíduo ou objeto afastado de quem fala e próxima da pessoa com quem se fala. Em termos linguísticos, esse é um dêitico, uma vez que aponta para a coisa a que se refere, o referente. Esse espaço pode então indicar o pátio. Mas pode também ser o canto, o pequeno espaço, onde está escrita a frase. Não existir pode indicar uma situação lá vivida, que conduziu o efeito de outra expressão: “Você não existe!”. O sinal de exclamação chama para ênfase, traduz um tipo de emoção à frase e ortograficamente é usado para transmitir dor, espanto, entusiasmo, surpresa, arrebatamento (figura 1). 
Ficura 1. Texto grafado no chão do Pátio Humanidades. Fonte: Trabalho de campo, nov.2018.

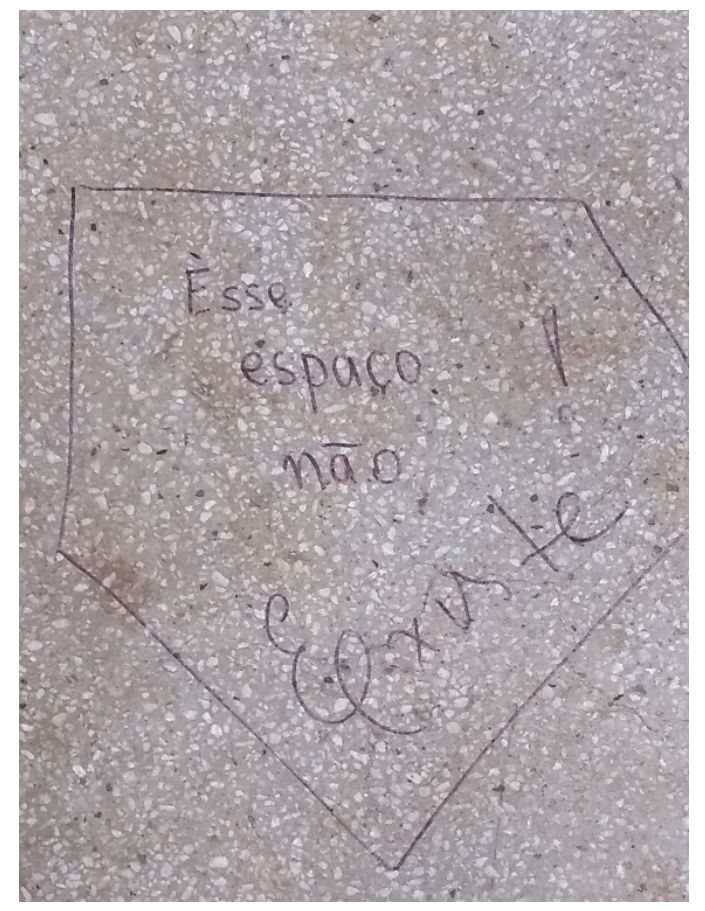

Mas que espaço não existe? A frase escrita no chão faz transitar entre a realidade e a ficção: o espaço cartesiano existe, mas uma determinada situação e a emoção que dele emana indica a negação disso. Apesar de não haver outra informação sobre o que pode sugerir esse discurso, outros que ali estão também sugerem essa ordem fictícia ou utópica do grego antigo, o não lugar. Ao longo do texto procuraremos elencar um conjunto desses exemplos que podem trazer à luz nossos argumentos.

A frase no chão que nomina a primeira parte desse artigo está localizada na fronteira pátio-bosque e a maior parte das pessoas que circulam nesse espaço passaria despercebida por ela. As portas que dão acesso do pátio para o IF estão sempre fechadas e comumente servem mais como espaço de reunião de alguns estudantes que se acomodam nos degraus das escadas para namorar, tocar violão, fumar e conversar. Há diferentes tipos de transeuntes nesse espaço: os que o utilizam para circular de um lugar para outro, o que se modificou ao longo do tempo com o processo de desativação do bosque - onde, até os anos 1990 e, talvez, o início dos anos 2000, circulavam pessoas tanto para acessar a biblioteca quanto para ir aos outros prédios, ao centro de convivência etc, constituindo um verdadeiro atalho ou uma trajetória alternativa. 
Há também os que ainda mantêm uma relação mais orgânica com o lugar, uma vez que o processo de ampliação da universidade fez com que os cursos de Ciências Sociais (FSC) e Faculdade de Filosofia (FAFIL) se mudassem para outro prédio e a FH ficasse no prédio que antes era dividido com a FAFIL. Isso fez com que parte das aulas ainda ocorressem em um mesmo lugar e não fossem deslocadas para os Centros de Aulas.

Ao mesmo tempo, a FIC também mantém um número de estudantes, docentes e técnicos circulando pelo pátio. Com o deslocamento do curso de Ciências Sociais para outro prédio, essas duas unidades - FH e FIC - passam a ser as unidades acadêmicas que mais possuem público organicamente conectado ao pátio, uma vez que o IF mantém fechadas as portas de acesso ao pátio, como já foi dito (cf. figuras 2).

Ficura 2: Acessos do IF ao Pátio Humanidades. Fonte: Trabalho de campo, nov.2018.

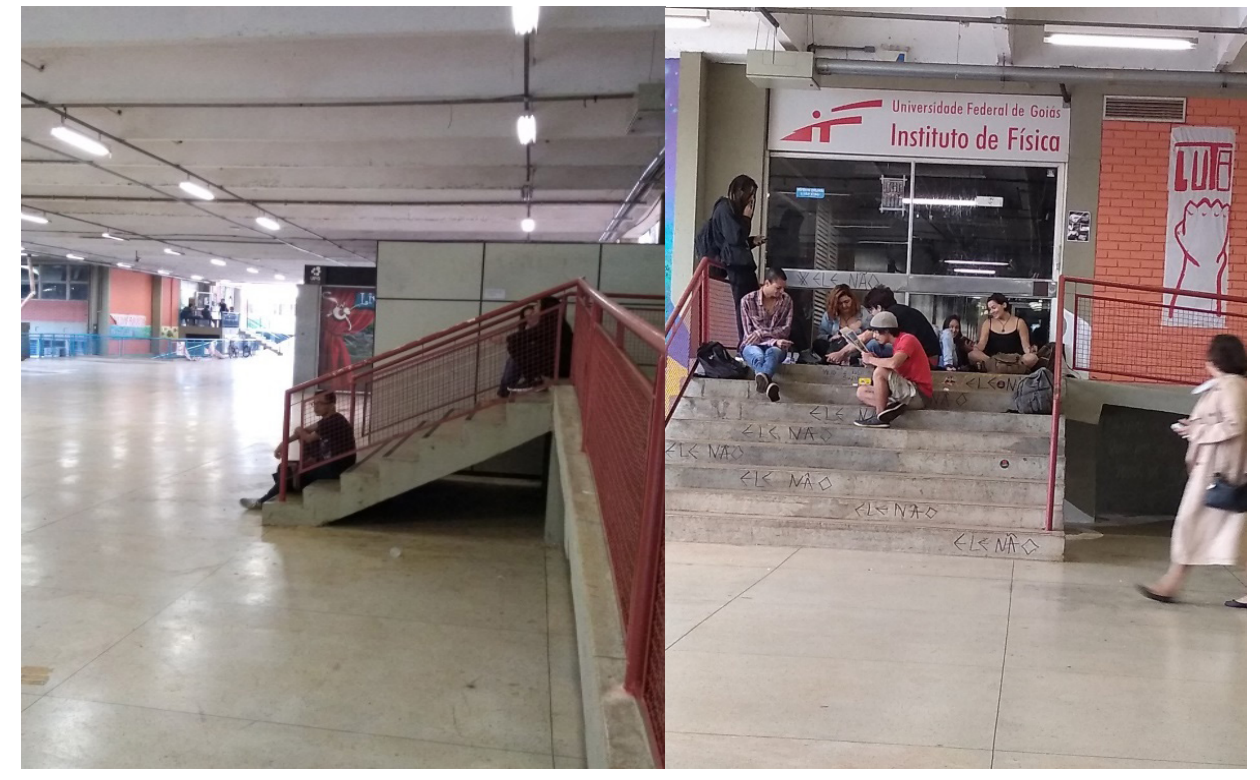

A relação do IF com o pátio está limitada ao acesso que se faria pelo bosque - que está desabitado, e pelas portas do instituto que se encontram permanentemente fechadas. Aos poucos esse fechamento conduziu os estudantes a outra forma de ocupação dessas entradas. As escadas foram apropriadas de maneira distintas - em frente à $\mathrm{FH}$, os estudantes se sentam com frequência, nos intervalos de aulas. Na outra porta, a presença de uma estrutura da empresa xerocopiadora, a Copysistem, dá um aspecto de esconderijo àquela entrada, atraindo pessoas para o carteado, descanso, namoro e também para fumar. 
Nossa proposta nesse texto é discutir o que as apropriações feitas desse pátio sugerem e o que elas escondem. Que tipos de discursos estão ali presentes e quais os sentidos que emanam desses discursos. Também se pode pensar nos discursos ausentes, ou seja, aqueles que não se encontram no pátio, mas que estão circulando em outros lugares da universidade, da cidade, no mundo social. É esse o objetivo sobre o qual nos debruçamos nesse trabalho.

\section{Perspectivas DisCURSIVAS DO ESPAÇO: A QUEM PERTENCEM OS DISCURSOS?}

\footnotetext{
"A abolição é a aurora da liberdade; esperemos o sol; emancipado o preto, resta emancipar o branco.” Natividade ficou atônita quando leu isto; (...) Relia a frase da carta e do discurso; (...) era uma ameaça ao imperador a ao império. (...)
}

Não atinou que a frase do discurso não era propriamente do filho; não era de ninguém. Alguém a proferiu um dia, em discurso ou conversa, em gazeta ou em viagem de terra ou de mar. Outrem a repetiu, até que muita gente a fez sua. (...) As próprias ideias nem sempre conservam o nome do pai; muitas aparecem órfãs, nascidas de nada e de ninguém. Cada um pega delas, verte-as como pode, e vai levá-las a feira, onde todos as têm por suas. (MACHADO DE ASSIS, 1992, p. 992-993)

Os sujeitos pensam que os discursos que proferem lhes pertencem. Não raro atinam que são de sua lavra. Soam-lhes inteiramente originais, fruto de sua capacidade única e autêntica de lhes imprimir uma marca indelével em seu corpo, em sua gramática, nos sentidos que deles ecoam, quando falados ou escritos. O excerto em epígrafe, apanhado do romance Esaú e Jacó, vai nessa direção ao discernir, por meio da astúcia do narrador, que o aturdimento da mãe em razão da ousadia do filho de proferir, em tempos de monarquia, a máxima: "A abolição é a aurora da liberdade; esperemos o sol; emancipado o preto, resta emancipar o branco", não se justifica. Antimonarquista, este discurso fora tomado pelo filho como próprio. Não era propriamente sua a ideia que exalava, ainda que a fizesse do seu jeito, que lhe desse um colorido e uma tonalidade que sugerisse um laivo de autoria. Em outras palavras, os sujeitos teriam a ilusão, como as personagens Paulo e sua mãe, Natividade, de serem os autores das ideias que defendem. 
$\mathrm{Na}$ verdade, as ideias que permeiam os discursos dos sujeitos são provenientes das formações sociais nas quais se inserem desde muito cedo, dos grupos sociais a que pertencem, de modo que a consciência individual de cada um sobre as coisas é formada pelas interações sociais de que participam ao longo da vida. Contudo, não se pode negar que as mesmas ideias com as quais os sujeitos se identifiquem assumam um contorno próprio, autoral, resultado da capacidade de eles as proferirem segundo um estilo singular.

A compreensão machadiana sobre a natureza discursiva é a que procuramos perseguir neste trabalho, com o fito de deslindar os discursos inscritos no espaço do Pátio Humanidades. Em termos teóricos, a perspectiva aqui adotada se alinha à semiótica de base bakhtiniana (1992 e 1997) ao postular que os discursos são o resultado de uma construção histórica da qual participam os sujeitos de diferentes esferas sociais. De sorte, que os discursos, por serem semióticos e ideológicos, resultam da força dialógica que anima as interações sociais. Para Bakhtin (Volochinov),

a palavra penetra literalmente em todas as relações entre os indivíduos, nas relações de colaboração, nas de base ideológica, nos encontros fortuitos da vida cotidiana, nas relações de caráter político, etc. As palavras são tecidas a partir de uma multidão de fios ideológicos e servem de trama a todas as relações sociais em todos os domínios. (BAKHTIN (VOLOCHINOV), 1992, p. 41)

Em princípio, pode-se dizer que o Pátio Humanidades é uma espécie de vão livre entre dois edifícios. Trata-se de lugar em que se manifestam discursos sobretudo (re) produzidos por estudantes de cursos da área de humanas, como Jornalismo e História. As paredes e mesmo o chão do pátio acolhem seus desenhos, pinturas, gestos, dizeres e não ditos, inscrições sobre as quais é preciso se debruçar como em achados arqueológicos que evocam sentidos ao comunicarem, dentre outras coisas, a que discursos estão vinculados, ainda que não seja essa a intenção de seus "autores". Eis uma imagem do Pátio Humanidades (figura 3): 
Ficura 3: Plano geral do Pátio Humanidades. Fonte: Trabalho de campo, nov.2018.

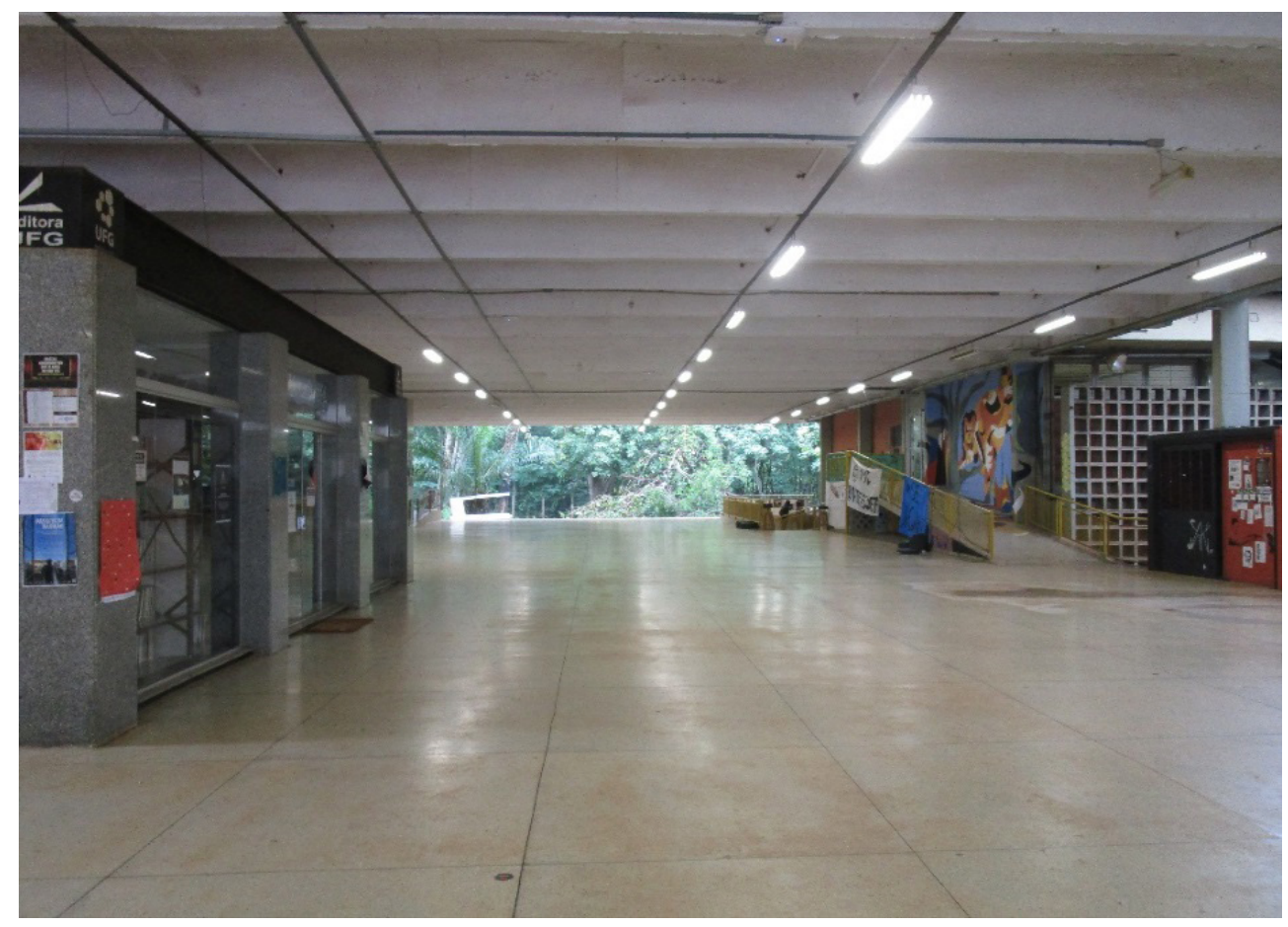

À esquerda da imagem fotográfica, encontra-se a livraria da Editora da UFG; à direita, o prédio da Faculdade de História (anterior à imagem, não retratado pela foto) e, ao fundo, à direita, o prédio da Faculdade de Informação e Comunicação (FIC) e o bosque, fronteiriço ao pátio. Nosso córpus é formado pelas fotografias que fizemos como método e técnica de recolha das imagens do espaço que pretendemos compreender, o Pátio Humanidades. Isso significa que elas não estão isentas de certa intencionalidade, da perspectiva em que são retratadas, de modo que os sentidos que emanam das fotos têm a ver com os focos adotados pelos fotógrafos que, em síntese, têm por objetivo propor certa reflexão ao (à) leitor(a) sobre os usos, funções e sentidos de um espaço em particular. Nesse sentido, as fotos constituem um metadiscurso por meio do qual pretendemos discernir e mesmo fazer pensar a propósito dos discursos sobre os quais incide o nosso olhar. A esse respeito, Roland Barthes conclui que "No fundo, a Fotografia é subversiva, não quando aterroriza, perturba ou mesmo estigmatiza, mas quando é pensativa." (BARTHES, 1984, p. 62). No caminho para o pátio humanidades, no estacionamento, aos fundos da FIC, defrontamo-nos com os seguintes dizeres: 
Ficura 4: Vista da fachada da FIC junto ao estacionamento. Fonte: Trabalho de campo, nov.2018.

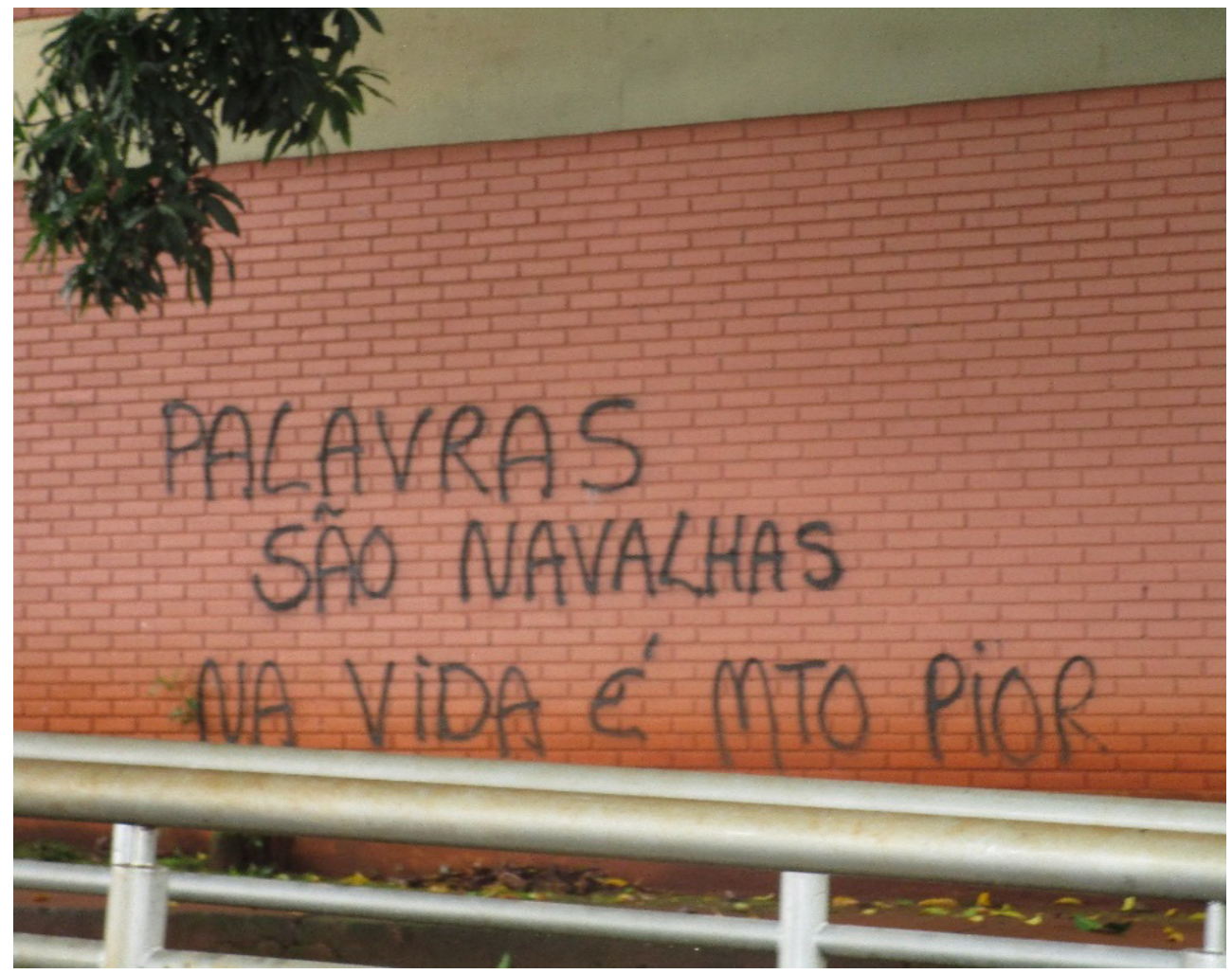

que nos fizeram pensar sobre os discursos que acabamos por documentar no interior do pátio humanidades. Quem são os autores desses discursos? Quem são seus interlocutores potenciais? Que efeitos de sentido produzem ou querem produzir por meio deles em seus interlocutores? O que querem comunicar?

Essa inscrição faz algum sentido no lugar em que se encontra, ou seja, na faculdade cujos cursos lidam com a palavra. Como um oráculo a ser decifrado, encerra uma espécie de aviso, de alerta para aqueles que trabalham ou trabalharão com a informação. Tendo a força de uma assertiva, a metáfora atribui às palavras um sentido que vem da analogia proposta, ou seja, as palavras podem cortar como uma navalha. Contudo, se o papel da comunicação é lidar com a informação, noticiá-la, nada se compara com a vida, com a sua crueza, que é o objeto da notícia. A reflexão proposta tem a ver com o objeto de conhecimento não apenas do jornalismo, mas também da história. A inscrição de certa forma procura subverter o que a ordem acadêmica pensaria sobre o poder da palavra, questionando-a, ao observar como essa perspectiva se distancia da vida que pode ser muito mais cruel. Acreditamos que de 
alguma forma os discursos (re) produzidos pelos sujeitos no Pátio Humanidades têm esse caráter subversivo, seja na forma como se configuram, seja nos suportes sobre os quais são inscritos, desenhados, pichados, pintados.

Atente-se para o fato de que alguns dos discursos buscam subverter a ordem estabelecida pela própria instituição universitária, simplesmente ao se apropriar semiótico-discursivamente das paredes do pátio como espaço de manifestação e de inscrição de enunciados e palavras de ordem de circulação nacional: Fora Temer, Marielle vive, \#Ele não etc (cf. figuras 5 e 6).

Ficura 5: Destaque para Fora Temer; Pelo fim da Militarização. Fonte: Trabalho de campo, nov.2018.

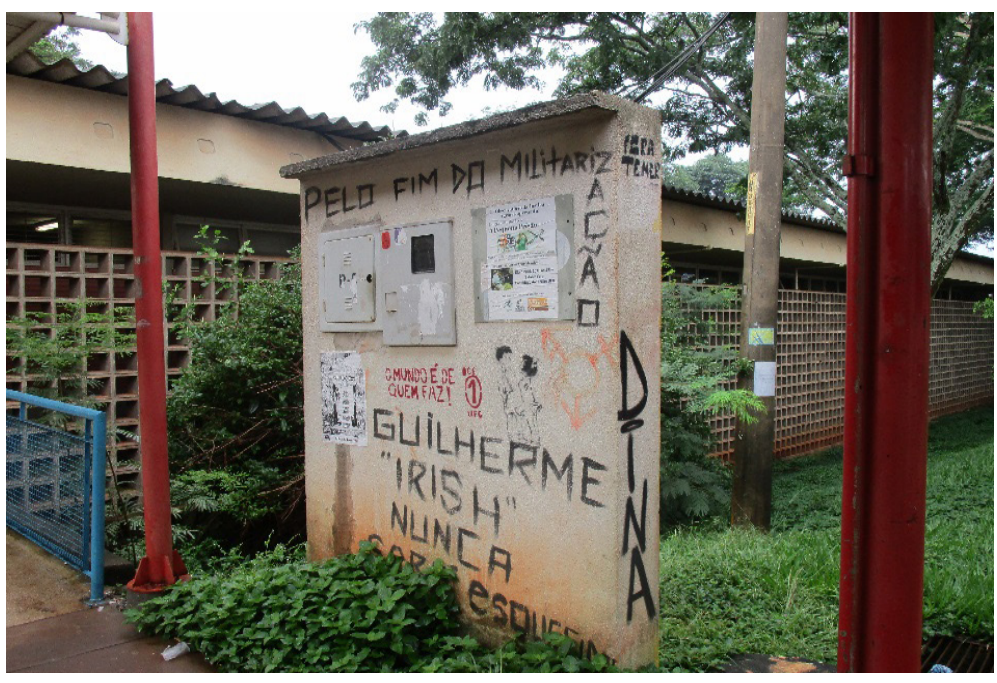

Ficura 6: Destaque para MARIELLE VIVE; NÃO VOTE, LUTE! CONSTRUA ASSEMBLEIAS POPULARES. Fonte: Trabalho de campo, nov.2018.

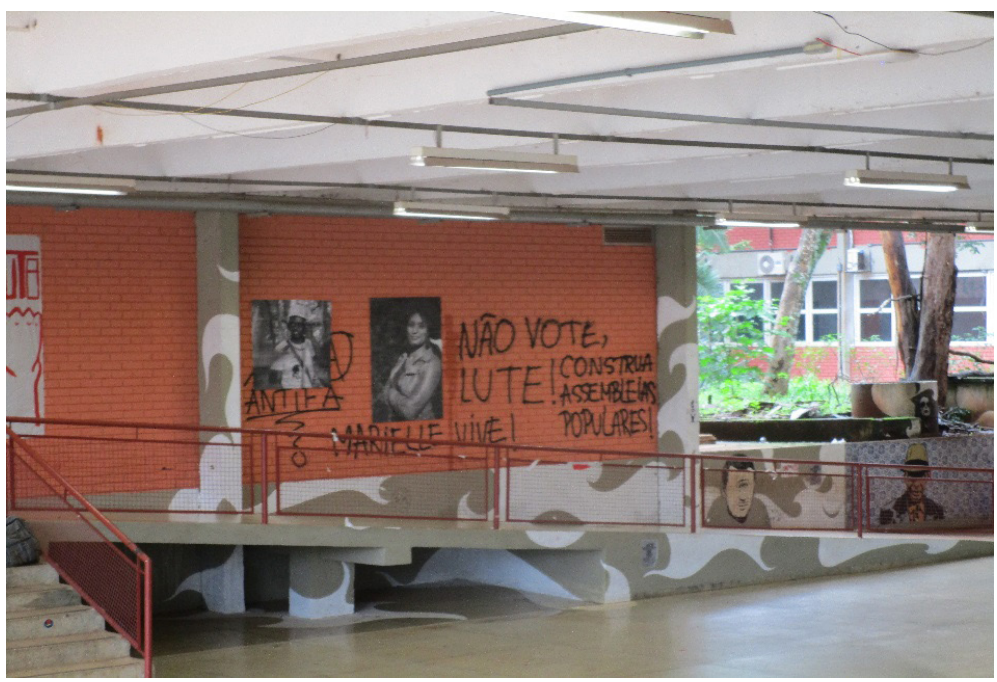


Observe-se que a adesão a discursos políticos de alcance nacional, que circulam em universidades e outras instituições públicas, aponta para a necessidade dos sujeitos explicitarem o seu posicionamento político que os identifica como grupo de orientação política progressista e de esquerda e os liga a outros coletivos que comungam das mesmas ideias, conferindo um efeito de unidade de pensamento, sobretudo aos acadêmicos de cursos da área de humanas. Mais do que sugerir que os discursos em destaque podem ser expressos naquele lugar e por aqueles sujeitos, pode-se afirmar que determinados discursos devem ser ditos, o que equivale dizer que há quase que uma obrigatoriedade de os sujeitos, dependendo do lugar de que enunciam, explicitar o vínculo com alguns discursos e, ao mesmo tempo, impedir ou rechaçar outros discursos que advenham de outras esferas sociais com as quais esses discursos divirjam. Conforme Foucault (1996), assumir determinados discursos e rejeitar outros, significa aderir a um corpo doutrinário ao quais os discursos estão inextricavelmente ligados, indicando a pertença dos sujeitos que os adotam e proferem. Nas palavras do autor,

a doutrina questiona os enunciados a partir dos sujeitos que falam, na medida em que a doutrina vale sempre como o sinal, a manifestação e o instrumento de uma pertença prévia - pertença de classe, de status social ou de raça, de nacionalidade ou de interesse, de luta, de revolta, de resistência ou de aceitação. A doutrina liga os indivíduos a certos tipos de enunciação e lhes proíbe, consequentemente, todos os outros; mas ela serve, em contrapartida, de certos tipos de enunciação para ligar indivíduos entre si e diferenciá-los, por isso mesmo, de todos os outros. (FOUCAULT, 1996, p. 42-43)

A doutrina relacionada ao viés político manifestada nos enunciados mostra a ligação dos sujeitos com as crenças políticas que professam do lugar em que enunciam, num dado horizonte histórico e social e em conformidade com o contexto enunciativo. O Pátio Humanidades é do domínio do discurso político. Seus enunciados reiteram um posicionamento de esquerda em relação a temas nacionais e, mesmo, estaduais, como o Pelo fim da militarização, discurso contrário à política implementada por Goiás de transferir a gestão das escolas de ensino fundamental e médio para a polícia militar do estado. Há que se considerar ainda outros domínios discursivos que coexistem com os enunciados de ordem política. Referimo-nos aos discursos cujos temas giram em torno da valorização de tipos humanos e personalidades públicas (cf. figura 11), de relações afetivas, de conflitos existenciais e de certo psicodelismo 
inscrito sobretudo em algumas pinturas relacionadas ao mundo lisérgico (cf, figura 7 e 8). Estes convivem com anúncios e propagandas de eventos que, em tese, interessariam ao público universitário (cf. figura 9). Vamos a algumas imagens de alguns desses enunciados:

Ficura 7: Plano Geral da FH com foco na pintura do painel. Fonte: Trabalho de campo, nov.2018.

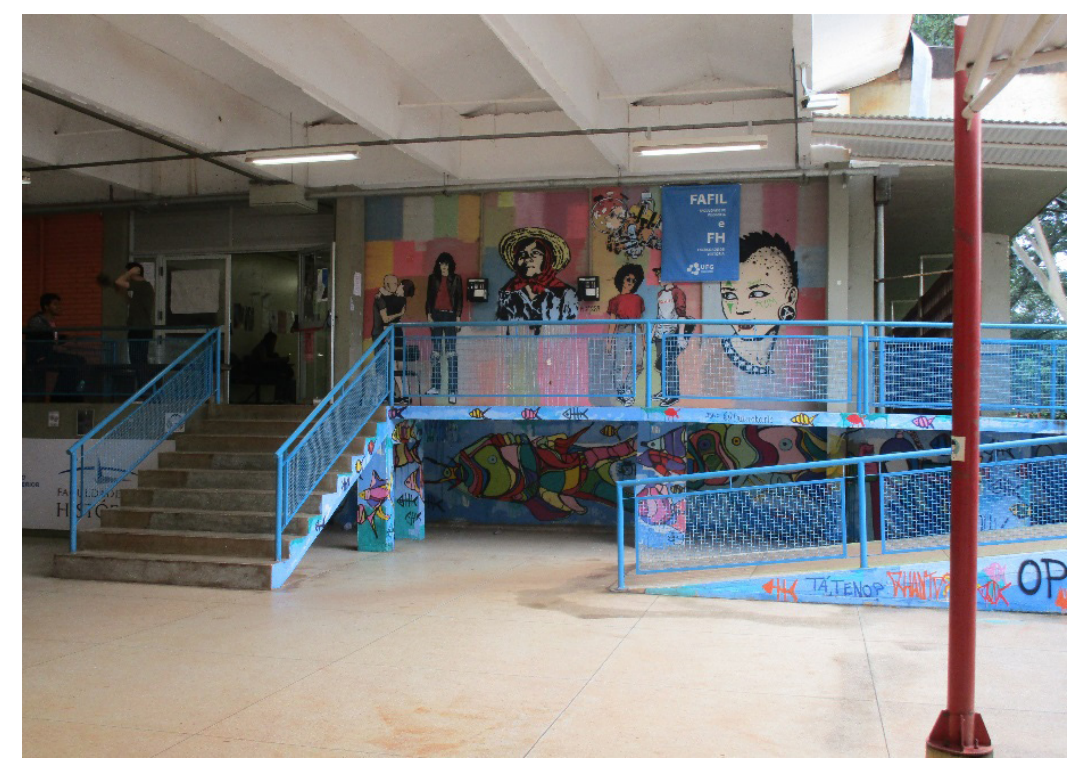

FicuRA 8: Primeiro plano de representação humana com mensagem psicodélica. Fonte: Trabalho de campo, nov.2018.

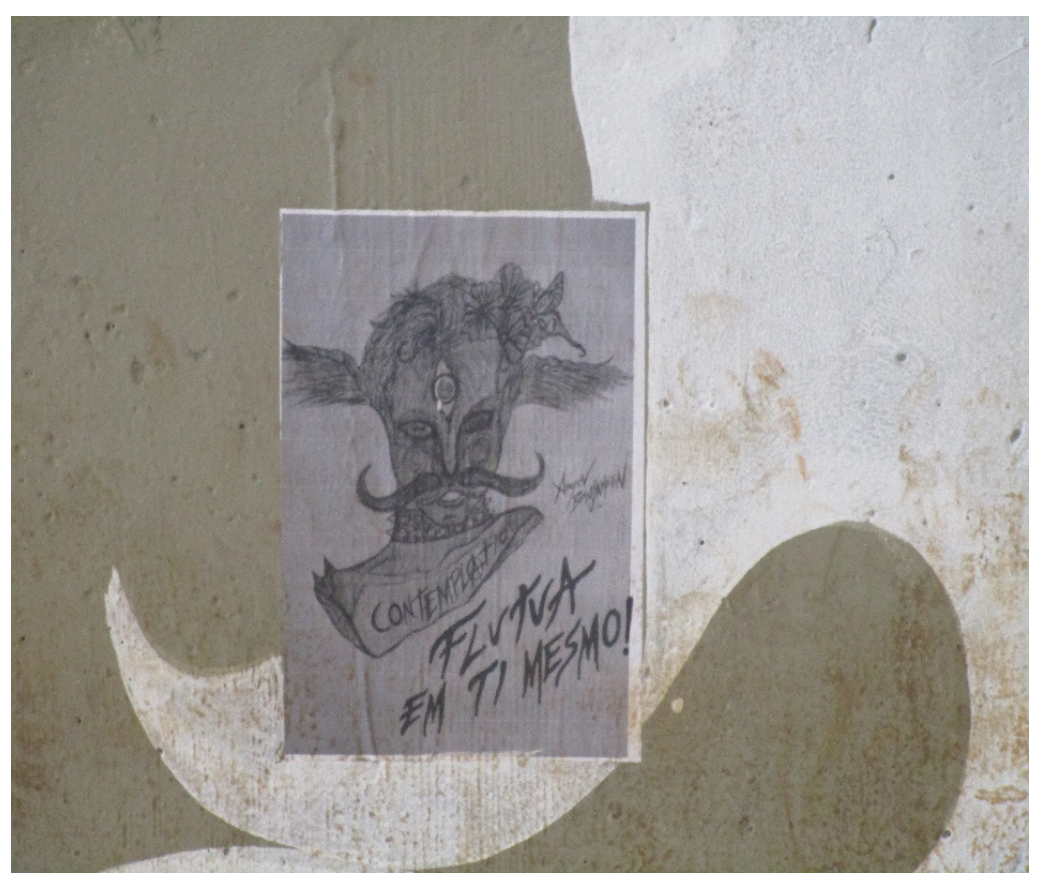


Ficura 9: Quadro de anúncios, propagandas e outros. Fonte: Trabalho de campo, nov.2018.

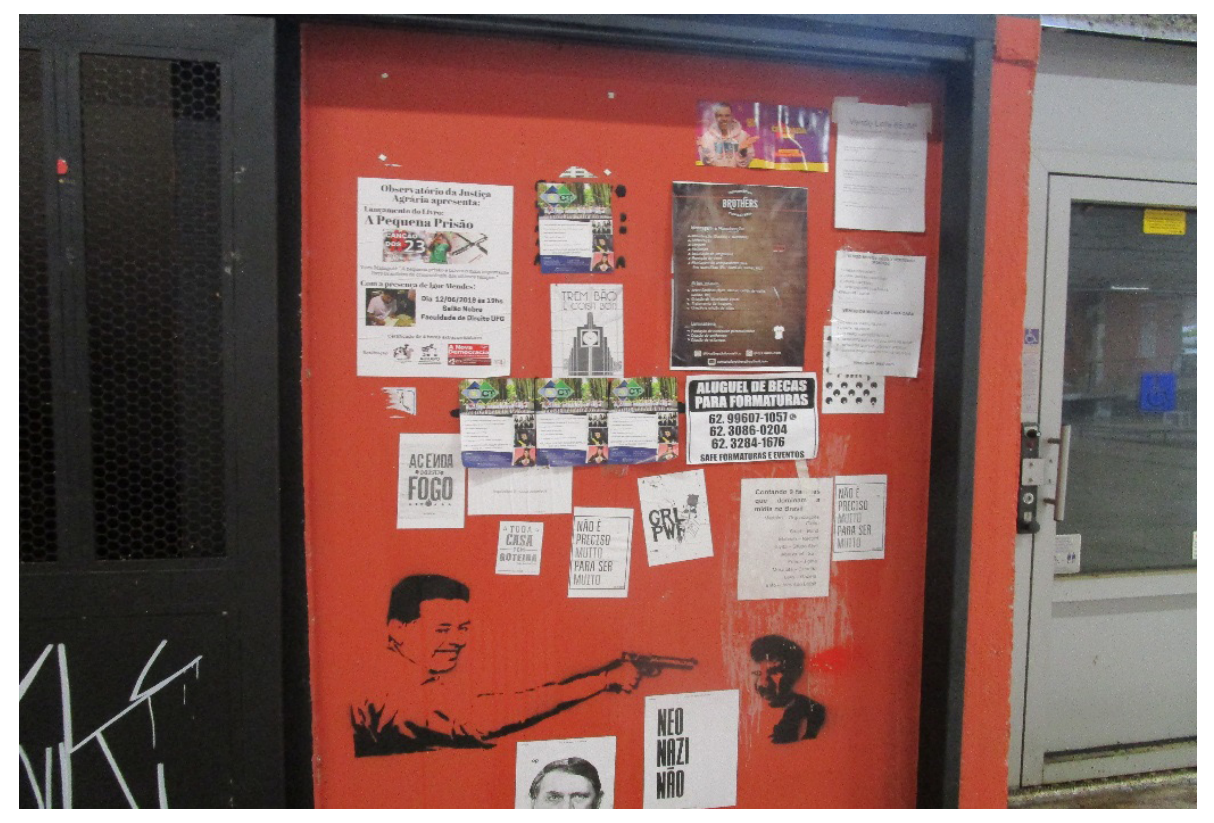

Ficura 10: Plano médio de desenho psicodélico. Fonte: Trabalho de campo, nov.2018.

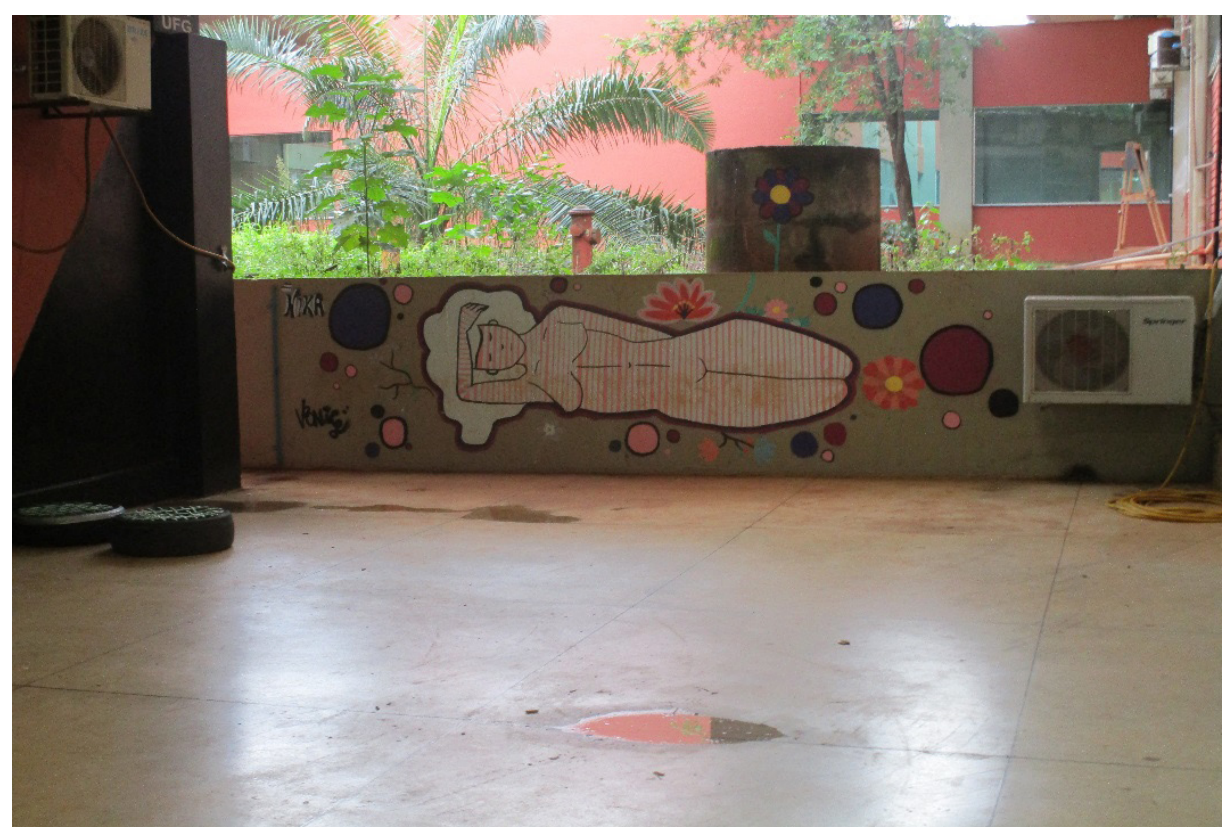

$\mathrm{Na}$ verdade, mesmo os enunciados que remetem a outros temas, como o painel acima (figura 7), que parece retratar pictoricamente tipos humanos e relações afetivas que encontram guarida no universo acadêmico, como a mulher negra, o casal enlaçado e a indígena de chapéu, comporiam grupos minoritários, incorporados pelo mesmo discurso político progressista e 
reconhecidamente de esquerda. Até mesmo aqueles que são da ordem do discurso lisérgico (figuras 8 e 10), parecem participar de um mesmo ethos, uma vez que fazem parte de um leque de comportamentos que devem encontrar abrigo, mesmo à revelia da instituição, na Universidade, entendida como espaço emancipatório e libertário.

Ficura 11: Reprodução de foto da vereadora Marielle. Fonte: Trabalho de campo, nov.2018.

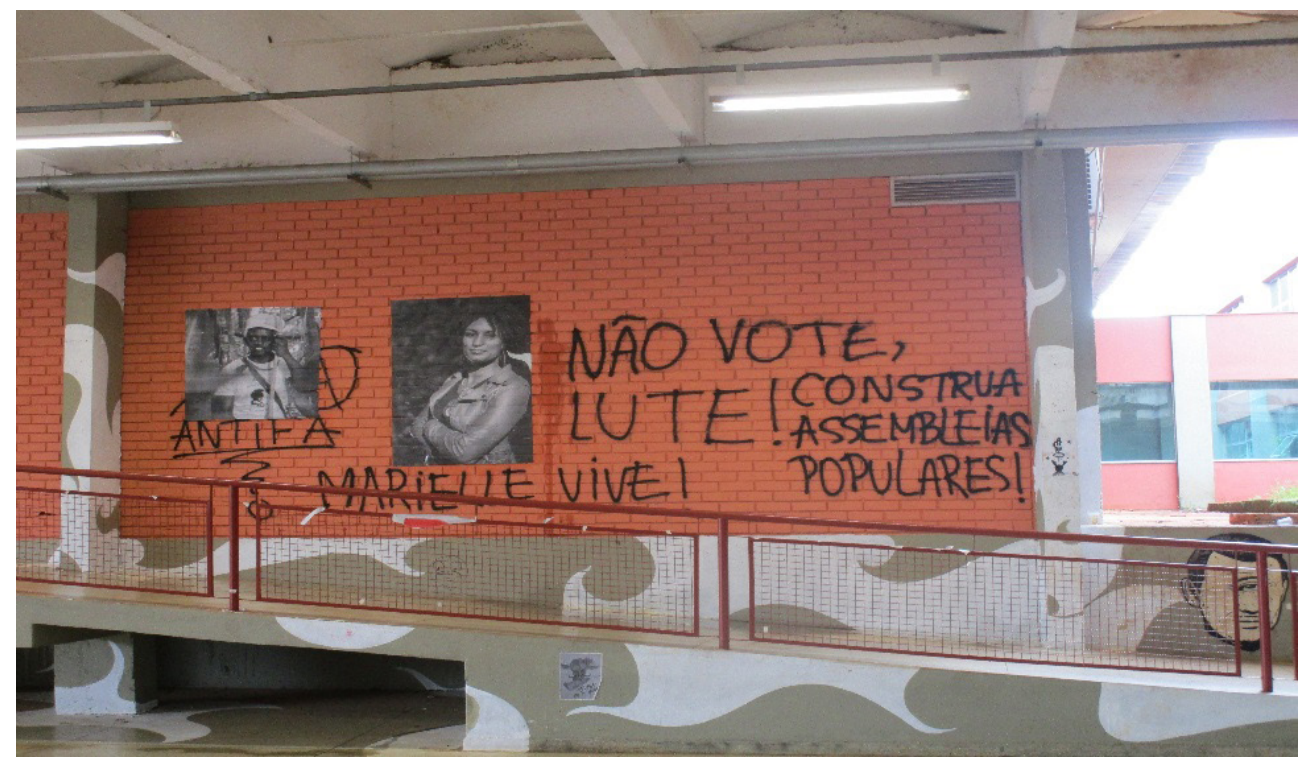

A reprodução de figuras públicas engajadas em lutas sociais, como a vereadora carioca Marielle, assassinada no início de 2018, reforça a pertença dos sujeitos às causas de alcance político-social e, possivelmente, à orientação política de seus cursos.

Em virtude disso, o Pátio Humanidades reúne enunciados que remetem ao que podemos denominar em síntese de discurso progressista, cujos temas se somam às demandas de movimentos sociais com os quais os sujeitos, sobretudo os estudantes da FIC e da FH, se identificam. De certa forma, explicitando esses enunciados com os quais se identificam, os acadêmicos fazem do espaço do pátio um lugar próprio, no qual não podem coexistir discursos com os quais não concordem e que rivalizem com as ideias progressistas que defendem. Esse predomínio de um viés discursivo acaba por silenciar outros discursos que não poderiam coexistir com esses enunciados de orientação progressista e de esquerda. É possível que haja na universidade outros espaços 
e outros tipos de manifestações que viabilizem a circulação de outros discursos que divirjam daqueles que compõem a face do Pátio Humanidades.

\section{Considerações Finais}

O espaço do pátio humanidades é aberto nas suas diferentes direções e se conecta a uma área verde de um lado e a uma escada do outro. Nas direções opostas os prédios também são intercalados com acessos arborizados o que, do ponto de vista arquitetônico, tem função de iluminar e conectar os ambientes construídos à rica diversidade arbórea que existe no câmpus. É por meio da descrição dessa paisagem que nos inspiramos à conclusão desse texto. A pretensão é de que ele estimule os olhares dos seus leitores para os espaços em que circulam na universidade, para os discursos que neles se instalam. Desde os painéis expostos nos pátios, nas faixas dependuradas das entradas do câmpus, os bilhetes anônimos de portas de banheiros, os desenhos grafados no chão e mesmo a forma com que as pessoas que circulam nesse espaço - o câmpus, seus vãos, pátios, corredores etc - o constroem e o vivenciam.

O desafio será sempre aprender a olhar e ver, aprender a olhar e compreender. A maneira como se dá a produção da vida universitária, historicamente, a mudança de ritmo, a instalação de um tipo de tempo reduzido a ciclos fragmentados onde a aula e o intervalo são esferas desse fragmento submete a vida a uma hierarquização onde as vivências podem ser importantes ou desimportantes, como sugere Lefebvre (1981). Porém, se o cotidiano pode ser o lugar de uma alienação ele também tem a potência da resistência.

Assim como no espaço urbano de um modo geral, os grupos que freqüentam o ambiente da universidade expressam de diversas maneiras suas concepções éticas, estéticas e políticas, confirmando, de certa maneira, as potencialidades deste espaço como lugar de alçar novos graus de compreensão do mundo.

Esperamos que o nosso texto inspire o aumento das brechas de resistências tão necessárias nos tempos de agora. 


\section{REFERÊNCIAS BIBLIOGRÁFICAS}

ANDRÉ, Karina. Croqui gráfico do Pátio Humanidades. Goiânia, 2018 (inédito).

BAKHTIN, Mikhail e VOLOCHINOV, V. N. Marxismo e filosofia da linguagem. São Paulo: Hucitec, 1992.

BAKHTIN, Mikhail. Estética da criação verbal. São Paulo: Martins Fontes, 1997.

BARBUY, Santiago. O espaço do encontro humano. São Paulo: E.C.E. 1980.

BARTHES, Roland. A Câmara clara. Rio de Janeiro: Nova Fronteira, 1984.

DE PELLEGRIN, Ana. Os contrastes do ambiente urbano: espaço vazio e espaço de lazer. Mestrado em Educação Física. Faculdade de Educação Física, Universidade Estadual de Campinas, Campinas, 1999.

FOUCAULT, Michael. A ordem do discurso. São Paulo: Loyola, 1996.

LEFEBVRE, Henri. O fim da História. Lisboa: Publicações Dom Quixote, 1981.

LIMA, Mayumi Souza. A cidade e a criança. São Paulo: Nobel, 1989.

MACHADO DE ASSIS, J. M. Esaú e Jacó, in: Obras completas. Rio de Janeiro: Nova Aguilar, 1992.

MAGALHÃES, Coelho Leandro. O Câmpus Universitário como equipamento singular do meio urbano: Ensaio em Três Rios, Brasil. Mestrado Integrado em Arquitetura e Urbanismo. Faculdade de Ciência e Tecnologia, Câmpus Fernando Pessoa, Porto, 2014.

MAGNANI, José Guilherme Cantor. Festa no Pedaço. São Paulo: Brasiliense, 1984.

MARX, Karl. Manuscritos econômico-filosóficos. São Paulo: Boitempo, 2004.

SÁNCHEZ VÁZQUEZ, Adolfo. Convite à estética. Rio de Janeiro: Civilização Brasileira, 1999.

TUAN, Yi-Fu. Topofilia: um estudo da percepção, atitudes e valores do meio ambiente. São Paulo: DIFEL, 1980. 